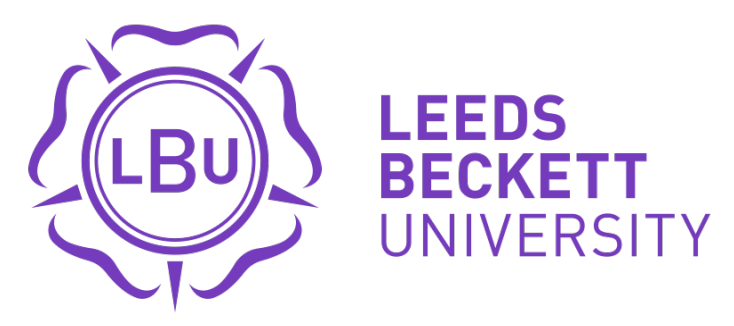

Citation:

Kime, NH and Pringle, A (2018) Exercise and physical activity in people with Type 1 diabetes: the importance of behaviour change. Diabetes Research and Clinical Practice, 138. pp. 282-283. ISSN 0168-8227 DOI: https://doi.org/10.1016/j.diabres.2018.02.024

Link to Leeds Beckett Repository record:

https://eprints.leedsbeckett.ac.uk/id/eprint/4763/

Document Version:

Article (Accepted Version)

The aim of the Leeds Beckett Repository is to provide open access to our research, as required by funder policies and permitted by publishers and copyright law.

The Leeds Beckett repository holds a wide range of publications, each of which has been checked for copyright and the relevant embargo period has been applied by the Research Services team.

We operate on a standard take-down policy. If you are the author or publisher of an output and you would like it removed from the repository, please contact us and we will investigate on a case-by-case basis.

Each thesis in the repository has been cleared where necessary by the author for third party copyright. If you would like a thesis to be removed from the repository or believe there is an issue with copyright, please contact us on openaccess@leedsbeckett.ac.uk and we will investigate on a case-by-case basis. 


\title{
Exercise and physical activity in people with Type 1 diabetes: the importance of behaviour change
}

\author{
Kime, N. H.; Pringle, Andy
}

Healthcare professionals are at the forefront for delivering public health messages and promoting healthier living amongst people with Type 1 diabetes. This includes encouraging individuals with Type 1 to be more physically active. However, healthcare professionals do not always know what to advise people with Type 1 when asked about incorporating physical activity into their lives [1].

Riddell, Gallen and colleagues produced the recent consensus statement on exercise management in Type 1, which represents the first set of guidelines to be produced for healthcare professionals on managing Type 1 and exercise [2]. This has evolved from the Juvenile Diabetes Research Foundation (JDRF) Type 1 Diabetes Performance in Exercise and Knowledge (PEAK) curriculum. The JDRF PEAK curriculum was developed following research undertaken by JDRF in the United States. This identified a lack of knowledge and support amongst health professionals around exercise management for those with Type 1 who wished to be more active. The curriculum was developed over 3 years and included training of a faculty group to deliver the programme. The UK programme was a collaboration between Exercising for Type 1 Diabetes (EXTOD) and JDRF PEAK, utilising, but not delivering all the PEAK programme content and incorporating some of the PEAK faculty alongside EXTOD.

As a result of this joint collaboration between EXTOD and JDRF PEAK, new standards for diabetes care during exercise have been established [3, 4]. EXTOD and JDRF PEAK are to be commended for the valuable work they are doing around Type 1 and exercise and for initiating the education of healthcare professionals and people with Type 1 about the management of the condition and exercise. This is an encouraging step towards making sure healthcare professionals and people with Type 1 are as informed as they can be. However, the education of healthcare professionals and people with Type 1 on the risks and benefits of exercise, as well as management strategies, is only one part of a complex scenario.

The authors were delegates at the 'EXTOD/PEAK: Exercising for type 1 diabetes and performing at your PEAK conference' held in Birmingham, United Kingdom, on October 13th, 2017 [5]. In the sessions we attended, the programme was dominated 
by the science of exercise and Type 1. This is an important element of the education of healthcare professionals, including how the science of Type 1 applies to people with Type 1 across the physical activity participation continuum. In our view, the programme needed to have greater applicability for the average person with Type 1 who just wants to increase their activity around daily active living and recreation [6]. They want to be more active (i.e. do the gardening, play with their children, walk to the shops), but not necessarily exercise (go to the gym, cycle) or participate in sports.

Other important areas are the (i) contribution of behavioural theory and (ii) effective intervention strategies. Encouragingly, Riddell and Gallen indicate that greater effort is required to better understand and overcome the observed barriers to regular physical activity [4]. Likewise, Greener highlights what healthcare professionals can do to support people with Type 1 to be more active [7]. We particularly welcome Riddell and Gallen's suggestion that progress is being made through the use of innovative tools and strategies, including those from the behavioural sciences. These disciplines play a crucial role in understanding and helping individuals with Type 1 to become physically active [8].

Physical activity is recognised as an important preventive behaviour [9], but the adoption and engagement of preventive behaviours such as physical activity is impacted by a complex and interrelated set of multi-level determinants $[10,11]$. This is especially so when physical activity is introduced into the management of Type 1. When healthcare professionals seek to help the Type 1 population individually and as a whole to become and remain physically active, arguably, the most important factor is the perspective of the individual. Understanding what determinants prevent and facilitate an individual's adoption and maintenance of physical activity is key [11].

As part of their education on physical activity and Type 1 diabetes management, it is essential that healthcare professionals are aware of the determinants that impact on physical activity. In our view, this is best understood from a holistic perspective [10] along with behaviour change strategies [11] and how to use these in conversations that are patient-centred. Trying to change an individual's course of action, where the emphasis is on compliance and the language used involves "should" and "tell them to" is unlikely to foster positive behaviour change. 
With this in mind and given their importance, future events such as the EXTOD/PEAK conference could include sessions on behaviour change and innovative implementation strategies for promoting physical activity, as well as exercise. These topics might be considered as important and valuable contributions alongside science.

1. Knight C, Lowe R, Edwards M, Yardley J, Bain S, Bracken R. Type 1 diabetes and physical activity: An assessment of knowledge and needs in healthcare practitioners. J Diabetes Nurs 2016; 20(8): 271-277.

2. Riddell MC, Gallen IW, Smart CE, et al. Exercise management in type 1 diabetes: a consensus statement. Lancet Diabetes Endocrinol 2017; 5: 377-390.

3. EXTOD. Available at : https://extodorg.ipage.com. [Accessed January 9th 2018].

4. Riddell MC, Gallen IW. Authors' reply. Lancet Diabetes Endocrinol 2017; 5(7): 493-494.

5. PEAK. Available at: https://abcd.care/PEAK-EXTOD-2017. [Accessed October 25th 2017].

6. Campbell MD, Kime N, McKenna J. Exercise and physical activity in patients with type 1 diabetes. Lancet Diabetes Endocrinol 2017; 5(7): 493.

7. Greener M. Exercise and type 1 diabetes: overcoming the barriers. Prac Diabetes 2017; 34(8): 277-279.

8. National Institute for Health and Clinical Excellence. Behaviour change at population, community and individual levels (Public Health Guidance 6). London: NICE, 2007.

9. Department of Health. Start Active, Stay Active. London: DoH, 2011.

10. Eldredge L, Markham C, Ruiter R, Fernandez M, Kok G, Parcel G. Planning health promotion programs: an intervention mapping approach, 4th edn. San Francisco, CA: Jossey-Bass, 2016.

11. Marcus B, Forsyth L. Motivating people to become physically active, 2nd edn. Champaign, IL: Human Kenetics, 2009.

We declare no competing interests.

Both authors contributed equally to the writing of this commentary. 